\title{
Management features of the innovative development of the enterprise taking into account cost-effective use of resources
}

\author{
Yu.V. Babanova ${ }^{1, *}$, V.P. Gorshenin ${ }^{1}$, and $A . Y u$. Dolinskaia ${ }^{1}$ \\ ${ }^{1}$ South Ural State University, Chelyabinsk, Russia
}

\begin{abstract}
Modern business is developing in the conditions of innovation-driven economy in which science and technology are the basis of competitive ability and a productive force. Most of the managerial decisions are taken in the context of limited resources and high uncertainty, because they depend on many factors, the dynamics of which is not always possible to estimate with reasonable accuracy. In this article special method is presented, which allows you to formalize the process of management decision, in terms of innovative product development. This method includes matrix analysis and vector calculus. The purpose of this method and model is to develop a set of alternative options for the product development and the selection of the most cost effective projects based on the integration of consumer requirements, innovative product specifications and the manufacturing capability of the organization (initial conditions for the project realization).
\end{abstract}

\section{Introduction}

Modern business is developing in the conditions of innovation-driven economy in which science and technology are the basis of competitive ability and a productive force. In contrast to the earlier stages, when the competitive position was determined by the closeness to resources, in today's world the key role is played by creativity and the ability to use opportunities beyond controlling the company's resources at this time, that is called - innovation. The transition from idea to innovation requires significant overhead. The term "resources" in accordance with the interstate standard GOST for resource saving 30166-95 [1] includes the value, stores and income opportunities. In general, the resources are divided into natural and economic (physical, labor, and financial).

An integral part of effective management is the economic, technical, scientific, practical and information activities, the complex of organizational and technical actions and activities that accompany all stages of the product life cycle, which are aimed at the efficient use and economical use of resources. In accordance with the national standard of resource saving GOST R 521042003 efficient use of resources defines resource economy or cost-effective use of resources [2].

\section{The main body}

Requirements for cost-effective use of resources are divided into three groups [2]. The first group includes requirements of resource quality defining perfection of processes, products, and services, such as the material composition and quantity of the used materials, weight, size, volume of products, etc. The second group includes the requirements of resource intensity (manufacturability); determining the possibility of achieving economic resource costs during the manufacture, repair and utilization of products, as well as carrying out various works and the provision of services taking into account the requirements of environmental safety. The third group includes requirements of resource efficient products, and also the ability to determine the economic resource costs in the operation, repair and utilization of products, as well as the performance of work and provision of services.

These groups of requirements are interrelated: - during product development, work and services planning (set project requirements of resource quality and resource efficient, recommendations on resource intensity);

- during the manufacturing of goods, performance of works and service provision (specified claim (control) requirements for resource intensity (for manufacturability); - during production operations, performance of works and provision of services (specified claim (control) requirements of resource intensity and resource efficient);

- during utilization of the products (resource intensity and resource efficient requirements are established).

Most of the managerial decisions are taken in the context of limited resources and high uncertainty, because they depend on many factors, the dynamics of which is not always possible to estimate with reasonable accuracy. This is caused by the lack of full information and the variability of the conditions of the organizational environment. Innovative projects are among the most high-risk to investments [3]. Any innovative project implemented by the company, is an open system. It is a part of a whole range of projects, ensuring the achievement of the eventual result. As a consequence there is a necessity not only for justifying the

Corresponding author: babanovayv@susu.ru 
competent management reasons to launch an innovative project, but also for drawing up an effective portfolio of innovative projects to ensure the achievement of strategic business goals, and determine the optimal sequence of start these projects.

After the analysis of the available scientific approaches, innovative tools and techniques of project management it was determined that not enough attention is paid for justifying the selection of the innovative project and its interrelation with other projects (implemented or planned for implementation in the enterprise). The solution of this problem is of scientific and practical interest, because it will simplify the process of selection and at the same time improve the quality of management decisions.

As part of the research work it was revealed that modern methods of justifying management decisions are advisory for the most part. Currently, for modeling economic situations, including an innovative direction, specialists increasingly used physical (mechanical) analogy, in particular, the tensor calculus, graph analysis [4] or the cognitive modeling, vector analysis, which allow us to understand what is happening in areas far removed from the natural sciences. On the basis of the scientific understanding the processes, it is possible to develop possible answers to the new changes. Excluding charges of mechanical philosophy, it may be noted that it is not about transferring the laws of physics and mechanics in economics, but the recognition of the effectiveness of the mathematical description and analysis of the systems under consideration and objects, using the positive experience, proven in physics and mechanics.

The team of authors of the International Faculty of the South Ural State University developed a method of integration and matrix analysis [5], based on international experience [6], which allows you to formalize the process of management decision, in terms of innovative product development. The proposed method combines matrix analysis and vector calculus. Matrix analysis is a tool that allows revealing logical connections between given parameters. Vector calculus allows interpreting the given data from matrix analysis in a graphical representation of the identified interrelations, and their consequences.

Management decision-making about selection of the innovative project can be viewed as a process consisting of ten stages (Table 1). The purpose of this process is to develop a set of alternative options for the product development and the selection of the most cost effective projects based on the integration of consumer requirements (because it is a source of income), innovative product specifications or a combination thereof (competitive advantage of the product), and the manufacturing capability of the organization (initial conditions for the project realization).

The selection of the innovative project is closely linked to the elements of cost-effective use of resources.

The process of management decision-making about choosing the innovative projects includes the following steps:

\section{Step I. Research objective statement}

For making the objective statement of the study is necessary to determine the object, which will be under directed attention. Thus, you choose a product which will be introduced innovative changes. This can be done in the following ways:

- based on the needs of the organization;

- on the basis of the actual requirements of the market;

- on the basis of future market needs.

After defining the object of research, it is necessary to give it a general characteristic. In the description, particular attention should be paid to the customer's needs, which would be satisfied the product under study. Analysis of substitute-goods (products that perform the same or similar function as the product in question) would allow more fully describe the consumer properties, ensuring customer satisfaction.

To identify the necessity of innovative changes in the product you should analyze the financial and economic results obtained by the organization from the output, and hypothesize about their positive change as a result of increased sales. Define SMART-goal of increasing sales volume and to define its place in the tree of the organization's goals.

The result of first step (the process of management decision-making on a choice of the innovative project) would be a reasonable objective of the research, which is reflecting the specialty of the product, trends and conditions of innovative changes.

\section{Step II. Consumer requirements analysis}

Defining features of the investigational product on the previous step, custom requirements and product properties satisfying these needs, you should use the survey and a tree diagram, prepared on its basis, to identify all consumer demands for which the client is able and willing to pay. You should define the requirements that determine demand. Moreover, you should remember about real and potential size of the demand.

The survey begins with the selection of the audience, which should represent the whole set of potential consumers of the product under research. This is called a representative sample [7]. Then conduct a survey of a selected audience; based on the results to determine what requirements must have a product so these people want to buy it. It is important to draw up a survey questionnaire, which is offered to your potential customers. The questionnaire card should contain questions with closed and opened answers. The respondent has a limited time for responses, only 3-5 minutes, if it would be longer, the qualities of responses will suffer. In addition, the formulation of the issues requires the participation of at least three experts: an engineer for this type of product, a psychologist or a linguist who knows how to ask questions, and an analyst who understands how the data will then be processed.

The survey results are presented in the form of a list of expected benefits that the customer can get from the product. After that it is necessary to make a classification of all expected benefits on the basis of "affinity". For each 
group of benefits is assigned the common name in the form of consumer demand $(\mathrm{CD} i)$. The presented set of requirements is ranked according to the selected scale (Rmni).].

Table 1. Process model of innovation project selection and development.

\begin{tabular}{|c|c|}
\hline \multicolumn{2}{|c|}{ Step I. Research objective statement } \\
\hline $\begin{array}{l}\text { Instruments: description of the } \\
\text { product and cross-section analysis }\end{array}$ & $\begin{array}{l}\text { Results: general description of the } \\
\text { product }\end{array}$ \\
\hline \multicolumn{2}{|c|}{ Step II. Consumer requirements analysis } \\
\hline $\begin{array}{l}\text { Instruments: imterview, ranking } \\
\text { the requirements }\end{array}$ & $\begin{array}{l}\text { Results: ranked list of consumer } \\
\text { requirements }\end{array}$ \\
\hline \multicolumn{2}{|c|}{ Step III. Product positioning } \\
\hline Instruments: benchmarking & $\begin{array}{l}\text { Results: Comparative table with all } \\
\text { competitive products }\end{array}$ \\
\hline \multicolumn{2}{|c|}{ Step IV. Design consumer features of the new Product } \\
\hline $\begin{array}{l}\text { Instruments: comparison study, } \\
\text { data fushion }\end{array}$ & $\begin{array}{l}\text { Results: list of consumer } \\
\text { requierements of the new product }\end{array}$ \\
\hline \multicolumn{2}{|c|}{$\begin{array}{c}\text { Step } V . \text { Selection of engineering specifications, ensuring project } \\
\text { consumer characteristics of the new product }\end{array}$} \\
\hline $\begin{array}{l}\text { Instruments: reverse engineering } \\
\text { analysis }\end{array}$ & $\begin{array}{l}\text { Results: list of engineering } \\
\begin{array}{l}\text { characteristics ensuring } \\
\text { characteristics }\end{array}\end{array}$ \\
\hline \multicolumn{2}{|c|}{$\begin{array}{c}\text { Step } V . \text { A comparison of the engineering and consumer } \\
\text { characteristics }\end{array}$} \\
\hline Instruments: matrix analysis & $\begin{array}{l}\text { Results: matrix of correlations } \\
\text { between engineering and consumer } \\
\text { characteristics }\end{array}$ \\
\hline \multicolumn{2}{|c|}{$\begin{array}{l}\text { Step VII. The correlation matrix of engineering characteristics and } \\
\text { selection of the most significant ones for the organization's goals }\end{array}$} \\
\hline $\begin{array}{l}\text { Instruments: } \\
\begin{array}{l}\text { analysis } \\
\text { correlation } \\
\text { importance }\end{array} \text { for defining the } \\
\end{array}$ & $\begin{array}{l}\text { Results: correlation matrix, } \\
\text { optimization of projects }\end{array}$ \\
\hline \multicolumn{2}{|c|}{ Step VIII. Estimation the difficulty of the project realization } \\
\hline Instruments: matrix analysis & $\begin{array}{l}\text { Results: list of actions for realizing } \\
\text { engineering characteristics }\end{array}$ \\
\hline \multicolumn{2}{|c|}{ Step LX. Estimation of economic efficiency of innovative projects } \\
\hline $\begin{array}{l}\text { Instruments: cost-effectiveness } \\
\text { analysis }\end{array}$ & $\begin{array}{l}\text { Results: business case for realizing } \\
\text { innovative projects }\end{array}$ \\
\hline \multicolumn{2}{|c|}{ Step $X$. Comparative evaluation of investment projects } \\
\hline $\begin{array}{l}\text { Instruments: ranking and } \\
\text { comparative analysis }\end{array}$ & Results: operational guidelines \\
\hline
\end{tabular}

The end result of the second step should be ranked identification of the most important product characteristics, according to the consumer's wishes.

\section{Step III. Product positioning}

At this step, the evaluation of satisfaction level of each consumer demand is happened. The evaluation is based on estimation of satisfying demands by similar competitive products or substitute-goods ( $\mathrm{P} c i)$, and own product before innovative changes (Ppi), if it had previously produced.

The used method is called the product benchmarking, and it enables the opportunity of the rating of consumer requirements for improving the research object parameters in order to increase its value for the customer and increase its competitiveness.

\section{Step IV. Design consumer features of the new Product}

Next step is to create a list of objective values in points for each consumer requirements (Pnpi), which the new product should obtain, to ensure a high level of demand.

Objective values of consumer requirements, without need of changes are assumed to be the base:

$$
P n p i=P p i
$$

Other targets are assumed equal to or higher than its competitors:

$$
P \text { Ppi } \geq P p i
$$

Using this data, the degree of improvement can be calculated (3):

$$
K p i=P n p i / P p i
$$

Here is also set the weight (Vmni) of each consumer requirement as the project goal (4):

$$
V m n i=K p i \times R m n i
$$

Further, the sum of weights of project goals ( $\Sigma V m n i)$ is determined. Also it is determined the weight percentage of each goal in the total amount: $(V m n i(o e))$ (5):

$$
V m n i(o e)=V m n i / \Sigma V m n i
$$

\section{Step V. Selection of engineering specifications, ensuring project consumer characteristics of the new product}

At the step $\mathrm{V}$, key engineering (technical) characteristics of the designed product $\left(\mathrm{EC}_{j}\right)$ are identified. These characteristics are not related, but they are enabling to secure previously selected consumer characteristics. In addition, for a deeper analysis of engineering characteristics their quantitative parameters are determined, which are suitable for the basis own product, 
competitors' products, and to designed your own product.

\section{Step VI. A comparison of the engineering and consumer characteristics}

A comparison of engineering and consumer characteristics is by means by a matrix where the customs' requirements $(\mathrm{CD} i)$ are laid vertically, and the engineering characteristics $\left(\mathrm{EC}_{j}\right)$ are laid horizontally. At the level crossing, the mutual coupling coefficients (A $i j)$ are indicated. Each coefficient shows: how much each engineering characteristic ensures the implementation of the consumer characteristics of the new product.

The coefficient, which reflects the strength of mutual influence of engineering and consumer characteristics, can vary from zero to one. One ("1") means the maximum (full) interaction between the factors. Zero ("0") means that any connection between factors is missing. Intermediate data values show the tendency of dependence.

Except the coefficient, reflecting the strength of mutual influence of engineering and consumer characteristics, it is necessary to know the orientation of this force. The direction of the force is reflected by sign: if with the growth of engineering characteristics, customer satisfaction increases, so the coefficient is positive, if it falls - the coefficient has negative sign.

The common sense, the theoretical concepts, expert judgment, published data, observation, experience, special planned experiment are commonly used to determine the value of the coefficient.

\section{Step VII. The correlation matrix of engineering characteristics and selection of the most significant ones for the organization's goals}

The implementation of some engineering characteristics affects the feasibility of others, it is necessary to reveal how many such characteristics affect each other. Next step is matching the engineering characteristics with each other. The interrelation between characteristics can be reflected through the coefficient $\mathrm{K} i j$. The shaded squares will be situated on diagonal, this area should not be filled, and the rest of the cells need to be filled. At this step for completing the table, experts of engineering services should be involved.

A comparison of data from the previous steps allows analyzing the connection between custom requirements and the interconnected engineering characteristics by using coefficients of interrelation Afij between 2 main coefficients $\mathrm{CD} i$ and $\mathrm{EC}_{j}(6)$ :

$$
A_{f i j}=A_{i j}+\sum_{i=1-n}^{j=1-k} K_{i j} \times A_{i j}
$$

where $\mathrm{i}(n)-$ number (quantity) of consumer requirements; $\mathrm{j}(k)$ - number (quantity) of engineering characteristics.
This step allows you to create a clarified matrix reflecting the tripartite interrelation between engineering characteristics and custom requirements.

\section{Step VIII. Estimation the difficulty of the project realization}

At this step it is necessary to identify activities that are essential to the innovative projects realization. After that you need to match these activities with the previously selected engineering characteristics, and the last ones are taken as the main goals of the project. As a result, the share of costs will be identified, which are required for the implementation of each project. The result of this step is a chosen innovative project, which is optimal for cost-result ratio.

\section{Step IX. Estimation of economic efficiency of innovative projects}

It is necessary to determine indicators of economic effectiveness of the project implementation for each engineering characteristics. Economic analysis of each project is held, this analysis allows determining the following parameters: cash flow, net present value, the rate of profit for capital, return on sales.

\section{Step $X$. Comparative evaluation of investment projects}

The purpose of the last step in the selection of the innovative projects is ranking all innovative projects according the feasibility of the projects and the order for their implementation.

The main goal of this process - the selection of the most economically efficient innovative project - is achieved. The scientific novelty of the suggested method (integrated-matrix analysis) consists of combining a number of matrixes that enable to justify an innovative project on basis of analysis of product utility, its competitive position and engineering capabilities of the enterprise. The main difference between suggested method and well-known method of structuring the quality function is the presence of analytical coefficients of interrelation between different engineering and consumer characteristics, which take into account the effect of influence. The score estimation of interrelation between the engineering characteristics is presented in basic model. This score is established by the expert.

Interpretation of the information obtained as a result of integrated-matrix analysis, can be carried through calligraphic display of norm-based scores.

The object of the study has a number of consumer requirements $Y i$, and as the result of interrelation it has one main goal $Y$ (total maximum level of consumers' requirements satisfaction). The following equation will be true (7):

$$
Y=\Sigma Y i
$$


If by every consumer requirement understand the purpose of the project and define through $\mathrm{Y} i$, and under $A_{\Sigma f i}$ - we define the range of sum of engineering characteristics of each (i-number) consumer requirement, the consumer demand can be represented as a vector (8):

$$
\Sigma Y i=A_{\Sigma f i} \times \cos \varphi i
$$

where $\varphi i$ - the angle between the direction of the main goal of the project and the vector of the $\mathrm{CD} i$.

This angle determines how this consumer requirement is consistent with the overall objective of the project and is associated with a rating of Rmni of this $\mathrm{CD} i$ in relation to the overall goal of the project. For example, the overall goal of the educational institution the graduation of highly skilled professionals and the basic consumer requirement is a minimum level of cost to the training of a good specialist. Rank of such consumer requirement will have a negative value with respect to the common goal. The degree of influence (or rating) is determined by the angle " $\varphi i$ " between the received direction to the early achievement of the maximum function $Y i$ and accepted direction of the consumer requirements' vector.

There are cases, for example for each factor: 1. $\varphi i=0^{0}$ : the requirement is directed to the early achievement of the maximum overall function $Y$;

2. $\varphi i=90^{\circ}$ : the requirement does not change the overall function $Y$;

3. $\varphi i=180^{\circ}$ : the requirement resist the achieving of the maximum overall function $Y$.

The remaining intermediate positions of the vector affect in different way to the achievement of the maximum overall function $Y$.

The general expression defining the impact of requirements (or vectors) to the final function $\mathrm{Y}$ has the form (9):

$$
Y=\Sigma\left(A_{\Sigma f i} \times \cos \varphi i\right)
$$

This is the basic equation of the harmonic connection of general objectives of the project and specific custom requirements.

To investigate the dependence of the required function $\mathrm{Y} i$ from variable factors, many of which in the initial state may not be appropriate to apply a numerical expression. To solve this problem it may be possible to use rationing arrangements of the valuation system. The procedure for calculation is described below:

1. Defined the engineering characteristics (ECj), affecting on this consumer requirement.

2. By calculation the amplitude value $\mathrm{A}_{f i j}$ for each inumber factor by $\mathrm{j}$-number engineer characteristic is determined. After that you use the estimation scale from 0 to 10 points; the sum of all the engineering characteristics for each i-number of custom requirements is displayed.

3. Calculate the factors in relative units.

4. In addition to the amplitude of the requirements, rating is affecting on the achieving of the common goals. It should be defined how the rating of each requirement is consistent with the main goal of the project.
You can accept that scores impact assessment index orientation customer requirements to achieve the common goal ranges from (10) - the direction of the vector is fully consistent with the direction of achieving the common goal; to $(-10)$ - the direction indicator completely counteracts the attainment of a common goal. With 10 points vector is analyzed in accordance with the general direction (angle error Public and Private vectors is equal to zero). At -10 points angle between the common and the private areas is $180^{\circ}$. With 0 points is equal to the angle between the vectors $90^{\circ}$, and this factor, although it has a certain peak value, but its course of action does not affect the rate in the overall result.

Let " $q$ " be the score point of the deviation's range of each requirement from achieving the common goal.

The value of scores is defined by experts:

- $\mathrm{q} a=10-$ the action of the particular requirement and the total target vector are in full agreement;

- $\mathrm{q} b=-10-$ the action of the particular requirement fully resist the total target of achieving goal;

- $\mathrm{q} c=3$ - partially agreed ( 3 out of 10 points).

5. We make the transferring the deviation of grading system $\mathrm{q} a$ ( $\mathrm{q} b, \mathrm{q} c$ ) into degrees of the misalignment angle of the total and partial vectors, based on these conditions:

- $(+10)$ points $=>\varphi=0^{0}$;

- 0 points $=>\varphi=90^{\circ}$;

- $(-10)$ points $=>\varphi=180^{\circ}$.

6. Determine the angle of alternation « $\langle\varphi$ [in angle degrees] of arbitrary vector of consumer requirements from the main purpose direction of taking into account the score mismatch «q» $(10)$ :

$$
\varphi=q \times R a+90
$$

where $\mathrm{R} a$ - is the coefficient of the conversion adopted points of vectors deviation from direction of achieving goals to general function to deviation amounts of the angles at the conditions:

1) $\mathrm{q}=-10=>\varphi=180^{\circ}$

2) $\mathrm{q}=0=>\varphi=90^{\circ}$;

3) $\mathrm{q}=10=>\varphi=0^{0}$.

Then, the conversion factor takes the form (11):

$$
R_{a}=\frac{\Delta \varphi}{\Delta q}=\frac{0-90}{10-0}=-9, \text { degree/ point }
$$

The function of the transfer of points to degrees takes the form (12):

$$
\varphi=(-9)[\text { degree/point }] \times q[\text { point }]+90 \text { [degree }]
$$

7. Further, the formula (13) produces the transferring the values of deviation angles " $\varphi$ " from degrees to radians and next step is calculation the values of $\cos \varphi$.

$$
\varphi[\operatorname{deg}]=\pi \times \varphi[\mathrm{deg}]
$$

8. According to the obtained values of the amplitudes of the ball distribution vectors $A_{\Sigma f i}$ and directions of their alignment with the overall objective function (the value of $\cos \varphi i)$ calculated the total value of the desired function the $\mathrm{Y} i$. This is a common normalized value of the objective function, a certain fixed state requirements 
and consumers $Y i$ ("a" factor "b" and "c"). Factors, in turn, defined parameters normalized amplitudes $\mathrm{A}_{\Sigma f i}$, and angles qi.

\section{Conclusion}

Thus, the proposed method of accounting treatment of interrelation between engineering characteristics, consumer characteristics and vector (harmonic) mapping of studied consumer requirements extend the analytical representation of project changes required to improve the consumer requirements of the object. In addition, these methods are calculated and graphically implemented in the program Microsoft Excel, which simplifies and extends their application to the development of innovative projects on the basis of resource.

The work was supported by Act 211 Government of the Russian Federation, contract № 02.A03.21.0011.

\section{References}

1. GOST 30166-95, Resource. Basic statements, Interstate standards (the Russian Federation) (2002)

2. GOST $R$ 52104-2003, Resource. Terms and definitions, Russian National Standard (2004)

3. S.A. Samovoleva, Technological Business, 4, (1999)

4. E.K. Kornoushenko, V.E. Maksimov, IPU Research study, 2-3 (1998)

5. Yu.V. Babanova, Economic analysis: theory and practice, 19(274), 45-51 (2012)

6. Akao Yoji, Quality Function Deployment (QFD). Integrating customer requirements into product design (Productivity Press, Portland, 1990)
7. W.G. Cochran, Sampling Techniques (Statistics, Moscow, 1976)

8. H.K. Rampersad, Managing Personal and Organizational Change: with Total Quality Management (Olymp-Business, Moscow, 2005)

9. H.K. Rampersad, TPS-Lean Six Sigma: Linking Human Capital to Lean Six Sigma: A New Blueprint for Creating High Performance Companies (Standards and quality, Moscow, 2009)

10. H.K. Rampersad, Total Performance Scorecard: Redefining Management to Achieve Performance with Integrity (Alpina Publisher, Moscow, 2005)

11. T. Luyster, D. Tapping, Creating Your Lean Future State: How to Move from Seeing to Doing (Standards and Quality, Moscow, 2008)

12. A. Farraharov, Energy and resourse saving in building and manufacturing sphere (2016)

13. O.N. Kolodina, Modern tendencies in economics and management: new opinion, 11, (2011)

14. A.V. Kleyman, A.Yu. Shumakov, Chelyabinsk State University Vestnik, 7, 132-138 (2008)

15. Y. Babanov, V. Gorshenin, Proc. Schumpeterian Readings, 70-76 (2014)

16. V. Gorshenin, S. Alyukov, SAE Technical Paper, 1, 22-25 (2014)

17. V.A. Barinov, Management in Russia and abroad Journal, 1, (2007)

18. S.A. Surkov, Yu. Boyko, A.A. Hrupalov, A.M. Lukashev, Management in Russia and abroad Journal, 1, (2007)

19. S.A. Evseeva, Problems of modern economics, 2(50), (2014)

20. R.S. Martynov, Resource-saving management methods at an industrial enterprise (2010) 